\title{
Reproductive Sink of Sweet Corn in Response to Plant Density and Hybrid
}

\author{
Martin M. Williams, $\mathbf{I I}^{\mathbf{1}}$ \\ U.S. Department of Agriculture-Agricultural Research Service, Global \\ Change and Photosynthesis Research, 1102 South Goodwin Avenue, \\ Urbana, IL 61801
}

Additional index words. crowding stress, shrunken-2, stress tolerance, Zea mays

\begin{abstract}
Improvements in plant density tolerance have played an essential role in grain corn yield gains for $\approx \mathbf{8 0}$ years; however, plant density effects on sweet corn biomass allocation to the ear (the reproductive 'sink') is poorly quantified. Moreover, optimal plant densities for modern white-kernel shrunken-2 (sh2) hybrids are unknown. The objectives of the study were to 1) quantify the effect of plant density and hybrid on the reproductive sink of sweet corn and 2) determine optimal plant densities for white-kernel $s h 2$ sweet corn. Field experiments were conducted across 2 years on 10 white-kernel sh2 hybrids grown at plant densities ranging from 4.3 to 8.6 plants $/ \mathrm{m}^{2}$. Increasing plant density negatively influenced reproductive sink characteristics of individual sweet corn plants, including linear decreases in ear shoots/plant, marketable ears/plant, ear length, filled ear length, ear mass/plant, and kernel mass/plant. Reproductive traits varied widely among hybrids, including ear mass $\left(15.6-20.6 \mathrm{Mt}^{-h^{-1}} \mathrm{a}^{-1}\right)$ and recovery $(32.3 \%$ to 42.4\%), which is the contribution of fresh kernel mass to total ear mass. Hybrids had a common response to plant density, whereby ear yield was optimized at $5.5 \mathrm{plants} / \mathrm{m}^{2}$ and gross profit margin was optimized at 6.1 plants $/ \mathrm{m}^{2}$. Plant density data from 586 growers' fields suggest current seeding rates have optimized the reproductive sink size for today's white-kernel sh2 hybrids. However, room exists for improving plant density tolerance, yield, and profitability.
\end{abstract}

Yield of all types of corn, including sweet corn, is the result of processes that accumulate plant biomass (the "source") and processes that allocate plant biomass to the ear (the reproductive "sink"). Yield can be limited by the source or sink; therefore, yield gains occur only with equivalent improvement in both the source and sink (Lee and Tollenaar, 2007). Several lines of evidence indicate corn is a sink-limited plant, including the fact that ear size, kernel size, and prolificacy have changed little over the last 80 years in the United States despite 6-fold yield gains (Egli, 2015). The sink limitation has been largely overcome in grain corn by improving plant density tolerance (also known as crowding stress tolerance) and planting modern hybrids at a higher plant density than their predecessors (Duvick, 2005; Egli, 2015; Mansfield and Mumm, 2014).

Improvements in plant density tolerance of sweet corn have lagged in comparison with

Received for publication 16 Oct. 2017. Accepted for publication 13 Nov. 2017.

I thank Nick Hausman, Jim Moody, the students who assisted with this research, and the seed companies listed in Table 1 .

Mention of a trademark, proprietary product, or vendor does not constitute a guarantee or warranty of the product by the U.S. Department of Agriculture and does not imply its approval to the exclusion of other products or vendors that also may be suitable.

${ }^{1}$ Corresponding author. E-mail: martin.williams@ ars.usda.gov. grain corn. Near the turn of the century, plant density recommendations for fresh market hybrids averaged 5.4-6.1 plants $/ \mathrm{m}^{2}$ (Morris et al., 2000; Rangarajan et al., 2002). For processing sweet corn, an average of 5.6 plants $/ \mathrm{m}^{2}$ was observed at harvest throughout the Midwest United States (Williams, 2012). By contrast, plant densities of grain corn during a similar time-period averaged 7.5 plants $/ \mathrm{m}^{2}$ (Smith et al., 2014) to as much as 12.8 plants $/ \mathrm{m}^{2}$ in record yield contests today (National Corn Growers Association, 2014).

Reproductive sink responses of grain corn to plant density have received considerable study (Boomsma et al., 2009; Cox, 1996; Tetio-Kagho and Gardner, 1988). Although sink size of grain corn is driven largely by kernel number and kernel mass (Lee and Tollenaar, 2007), other reproductive traits are commercially important to sweet corn. Specifically, marketable ear number and length are important in fresh market hybrids, whereas kernel mass and recovery (i.e., fresh kernel mass as a percentage of total ear mass) are important in processing hybrids (Tracy, 1993). How plant density affects the reproductive sink of sweet corn is poorly known. In general, ear mass, filled ear length, and recovery decrease at higher plant densities (Rogers and Lomman, 1988; Shelton and Tracy, 2013; Williams, 2012). A more detailed analysis of the reproductive sink response to plant density in sweet corn would be valuable as breeders improve plant density tolerance.

Most production of sweet corn grown for processing in North America uses yellow-kernel sh2 hybrids (Nick George, personal communication). White-kernel sweet corn is preferred from the mid-Atlantic through the southern United States (Tracy, 1993). Endosperm color is a simply inherited trait, with white recessive to yellow. A recent analysis of 26 popular sh2 hybrids showed that the single white-kernel entry had the lowest plant density tolerance (Williams, 2015). This observation calls into question the optimal plant density of whitekernel sh2 hybrids.

Given the gaps in knowledge about sink limitations in sweet corn, particularly for white-kernel hybrids, the objectives of the study were to 1) quantify the effect of plant density and hybrid on the reproductive sink of sweet corn and 2) determine optimal plant densities for white-kernel sh2 sweet corn.

\section{Materials and Methods}

Field experiments were conducted in 2015 and 2016 at the University of Illinois' Vegetable Crop Research Farm near Urbana, IL. A different field was used each year, whereby the preceding crop was soybean [Glycine $\max ($ L.) Merr.]. Soils were a Drummer silty clay loam (Fine-silty, mixed, superactive, mesic Typic Endoaquolls) averaging 3.2\% organic matter and a pH of 5.7. Before planting, $135 \mathrm{~kg} \mathrm{~N} / \mathrm{ha}$ was applied as urea and incorporated with a field cultivator. Sweet corn was planted on 76-cm rows on 19 May 2015 and 18 May 2016. Tefluthrin $\{(2,3,5,6$-tetrafluoro4-methylphenyl) methyl $(1 R, 3 R)$-rel-3[(1Z)-2-chloro-3,3,3-trifluoro-1-propenyl]2,2-dimethylcyclopropanecarboxylate $\}$ was applied in a t-band at planting to control corn rootworms (Diabrotica spp.). A preemergence treatment of $s$-metolachlor $\{2$-chloro- $N$-(2ethyl-6-methylphenyl)- $N$-[(1S)-2-methoxy1 -methylethyl]acetamide $\}$ plus atrazine (2-chloro-4-ethylamino-6-isopropylamino-1,3,5triazine) was applied after planting. Weeds escaping control from herbicides were removed as needed.

Germplasm. All 10 of the major North American sweet corn breeding programs were asked to identify germplasm for the experiment. Seeds of 10 white-kernel sh 2 processing hybrids were procured from five sources (Table 1). Maturity, as measured in days from planting to harvest, ranged from 76 to $80 \mathrm{~d}$. The 10 hybrids may represent the majority of white-kernel sh2 processing hybrids available in North America when the experiment was initiated, as evidenced by the fact that no additional hybrids were identified by the seed industry at that time.

Experimental approach. The experimental design was a split plot arrangement within a randomized complete block with four replications. Main plot treatment was assigned hybrid. Three-meter wide main plots consisting of four crop rows were divided into $9.1 \mathrm{~m}$ long subplots. Subplot treatments were assigned one of four target plant densities $\left(4.3,5.7,7.2\right.$, and 8.6 plants $\left./ \mathrm{m}^{2}\right)$. Plant densities were established by over-seeding each treatment $25 \%$ and hand-thinning as close as possible to the target plant density when plants had two visible leaf collars. 
Data collection. All data were collected from the center $6.1 \mathrm{~m}$ of the middle two rows of each subplot. At the onset of anthesis, the number of plants with emerged silks were counted until at least $50 \%$ of plants had silked; hereafter called the midsilk date. After the midsilk date, leaf area index (LAI) was estimated under full-sun conditions using a linear ceptometer (AccuPAR Linear Ceptometer; Decagon Devices, Pullman, WA). Harvest date of each hybrid was determined as $18-20 \mathrm{~d}$ after midsilk of the 4.3 plants $/ \mathrm{m}^{2}$ treatment.

At the time of harvest, total number of ear shoots and plant density were recorded. Marketable ears, measuring $\geq 4.5 \mathrm{~cm}$ in diameter were hand harvested from each subplot. Marketable ear number and ear mass were recorded. Ears were husked with an industry-grade husking bed (A\&K Development, Eugene, OR). Ten husked ears per subplot were randomly selected and measured from butt to tip (hereafter called ear length) and butt to the boundary between fully developed kernels and underdeveloped kernels near the ear tip (hereafter called filled ear length). All husked ears were weighed, then fresh kernels were cut from the cob with an industry-grade corn cutter (A\&K Development) and cob mass was recorded. Kernel mass was calculated as the difference between husked ear mass and cob mass, then adjusted to $76 \%$ kernel moisture based on the difference between fresh kernel mass and oven-dried kernel mass. Recovery was determined as the percentage of fresh kernel mass to green ear mass. Plant response was determined on the basis of area (e.g., no. $/ \mathrm{m}^{2}$ ) and individual plant (e.g., no./plant).

Gross profit margin to the processor $(\$ / \mathrm{ha})$ was calculated as described by Williams (2012). Specifically, gross profit margin reflects the value of cases of sweet corn produced per hectare less seed cost and contract cost for green ear mass. Assumptions to the model included $6.13 \mathrm{~kg}$ of fresh kernels per case, a wholesale price of $\$ 12$ per case, a seed cost of $\$ 3$ per 1000 kernels, and a contract cost of $\$ 110$ per Mt of green ear mass.

Plant density observed in contract fields. A sweet corn production dataset of an anonymous processor was used to relate optimal plant densities identified in this experiment to plant densities observed in contract fields. Fields were selected based on the following criteria: grown using a sh2 hybrid, for the years $2000-15$, and plant density had been quantified. A total of 586 fields met the three criteria.

Data analysis. Variances met analysis of variance (ANOVA) assumptions of normality and homogeneity. Response variables were analyzed by ANOVA using the Proc Mixed procedure of SAS, version 9.3 (SAS Institute, 2010). Years and replicates nested within years were considered random effects. Hybrid and plant density were considered fixed effects. When the hybrid effect was considered significant $(P<0.05)$, hybrid means were compared using protected, Bonferroni-corrected multiple comparisons
Table 1. Source and maturity of 10 white-kernel shrunken-2 sweet corn hybrids used in field trials near Urbana, IL.

\begin{tabular}{llc}
\hline Hybrid & \multicolumn{1}{c}{ Source } & Maturity $^{z}(\mathrm{~d})$ \\
\hline 1760MRW & Abbott \& Cobb & 80 \\
378 A & Illinois Foundation Seed, Inc. & 77 \\
7401 W & Abbott \& Cobb & 76 \\
CSHWP9-3 & Crookham Company & 77 \\
Devotion & Seminis & 78 \\
Glacial & Abbott \& Cobb & 77 \\
Heavenly & Syngenta & 77 \\
SV1580SC & Seminis & 80 \\
WSS3681 & Syngenta & 78 \\
XTH3174 & Illinois Foundation Seed, Inc. & 77 \\
\hline
\end{tabular}

${ }^{\mathrm{z}}$ Maturity based on days from planting in field trials, averaged across environments.

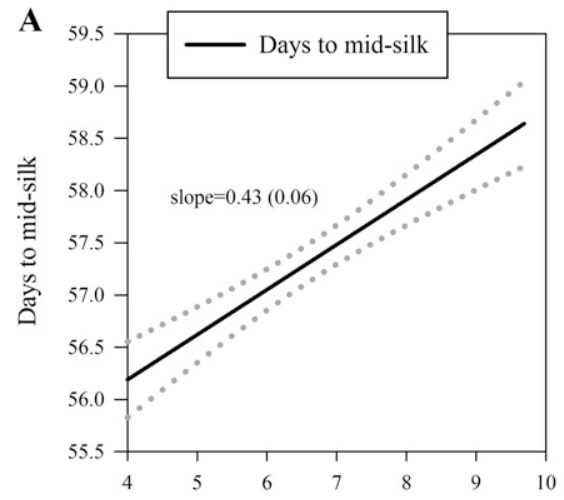

B

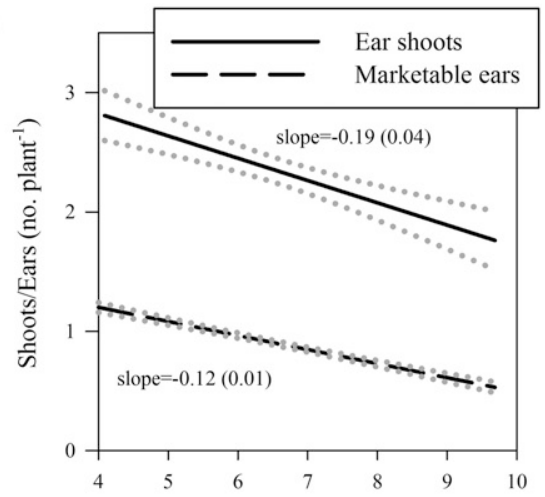

C
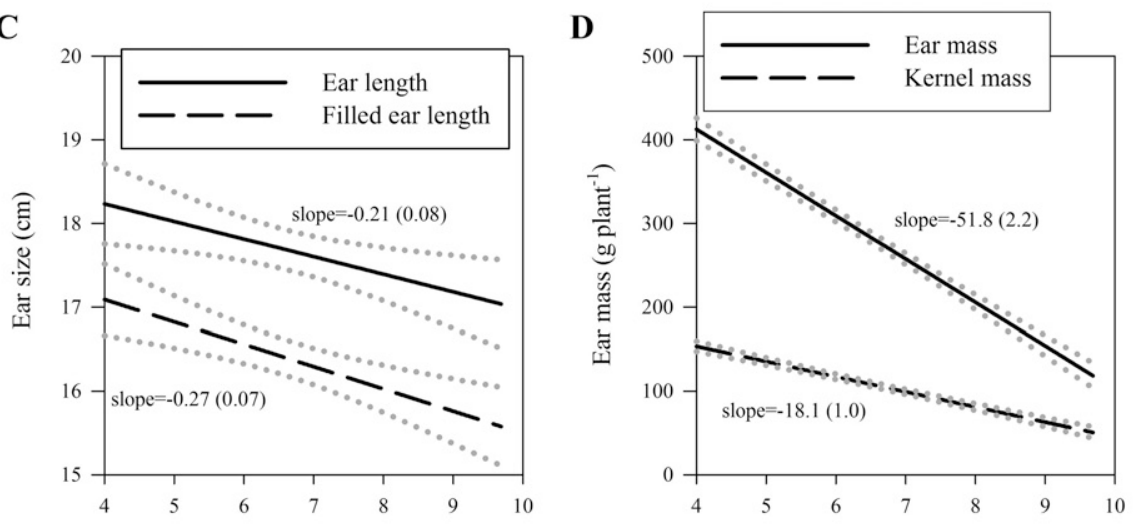

E
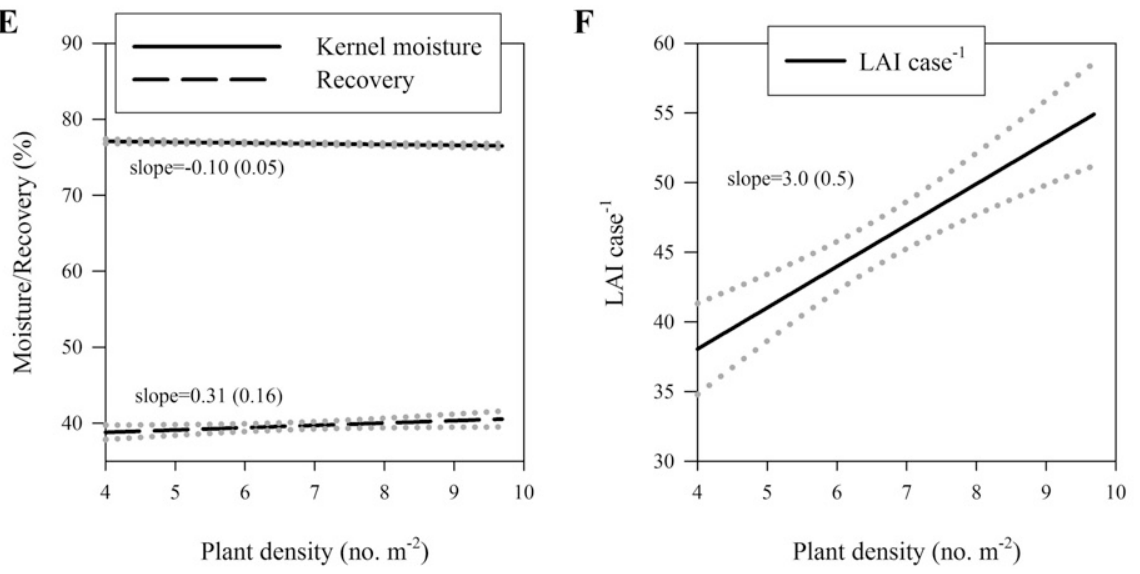

Fig. 1. Effect of plant density on days from planting to midsilk (A), number of ear shoots and marketable ears (B), ear length and filled ear length (C), ear mass and kernel mass (D), kernel moisture and recovery $(\mathbf{E})$, and leaf area index $(\mathrm{LAI}) /$ case $(\mathbf{F})$. Plant density effects are described with a linear model. Ninety-five percent confidence intervals and slope coefficients with SES in parentheses are presented. 
(Neter et al., 1996). When the plant density effect was significant, regression analyses were used to quantify relationships between plant density and crop response. Response variables were fitted to linear or quadratic models as a function of observed plant density using least-squares regression. Regression parameter estimates were used to characterize crop response to plant density, and predicted values were used to identify plant densities resulting in maximum ear yield and maximum gross profit margin. Regression analyses were performed in SigmaPlot 12.5 (SYSTAT Software Inc., Chicago, IL). A Pearson correlation analysis among crop responses was conducted. Probability values for correlations were calculated using the Bonferroni correction.

\section{Results}

No interactions were observed between hybrid and plant density (data not shown); therefore, crop response to only main effects will be presented.

Reproductive sink and plant density. Plant density had a significant effect on every measure of the reproductive sink of sweet corn $(P<0.001)$. A linear model was used to describe the effect of plant density on days to midsilk, ear shoots/plant, ears/plant, ear length, filled ear length, ear mass/plant, kernel mass/plant, kernel moisture, recovery, and $\mathrm{LAI} /$ case.

Plant development was delayed with increasing plant density. For instance, each additional plant $/ \mathrm{m}^{2}$ delayed time to midsilk by $0.43( \pm 0.06)$ days (Fig. 1A). Increasing plant density also resulted in subtle, yet significant, decreases in the number of ear shoots and marketable ears per plant. For instance, each additional plant $/ \mathrm{m}^{2}$ reduced the number of ear shoots and marketable ears by $0.19( \pm 0.04)$ and $0.12( \pm 0.01)$ per plant, respectively (Fig. 1B).

The size of ears present on plants at harvest was greatly affected by plant density. For instance, each additional plant $/ \mathrm{m}^{2}$ reduced ear length and filled ear length by $0.21( \pm 0.08) \mathrm{cm}$ and $0.27( \pm 0.07) \mathrm{cm}$, respectively (Fig. 1C). Ear mass lost 51.8 $( \pm 2.2) \mathrm{g} /$ plant with each additional plant $/ \mathrm{m}^{2}$, whereas kernel mass declined $18.1( \pm 1.0) \mathrm{g} /$ plant (Fig. 1D).

More subtle, yet significant, effects were observed on kernel moisture and recovery. Kernel moisture had a slightly negative relationship to plant density, whereas recovery had a slightly positive relationship to plant density (Fig. 1E).

Leaf area to produce one case of sweet corn increased sharply with plant density. For instance, $\mathrm{LAI} /$ case increased $3.0( \pm 0.5)$ units for each additional plant $/ \mathrm{m}^{2}$ (Fig. 1F).

Reproductive sink and hybrid. There was a significant effect of hybrid on every measure of the reproductive sink of sweet corn $(P$ $<0.001)$. Mean days to midsilk ranged from 55.9 to $60.2 \mathrm{~d}$ (Table 2). Although mean ear shoots/plant ranged from 1.88 to 3.04 , marketable ears/plant ranged from 0.72 to 1.06 .

The size of ears present on plants at harvest varied by hybrid. For instance, hybrid 1760MRW had the smallest ear mass/plant and kernel mass/plant, averaging 250 and $72 \mathrm{~g} / \mathrm{plant}$, respectively (Table 2). By contrast, hybrid SV1580SC had among the largest ear mass, averaging 333 and $115 \mathrm{~g} / \mathrm{plant}$ for ear mass and kernel mass, respectively.

Although hybrid 1760MRW had among the lightest ears, the hybrid also had among the longest ears. The hybrid averaged 18.6 and $17.5 \mathrm{~cm}$ for ear length and filled ear length, respectively, longer than most other hybrids (Table 2). Nonetheless, long ears did not contribute to recovery. Recovery of hybrid $1760 \mathrm{MRW}$ was $32.3 \%$; lower than all other hybrids. By contrast, the highest recovery hybrids were $378 \mathrm{~A}$, XTH3174, and WSS3681, which met or exceeded $42.0 \%$ recovery.

Ear yield varied widely among hybrids, too. The highest-yielding hybrid (i.e., SV1580SC) averaged $20.6 \mathrm{Mt} \cdot \mathrm{ha}^{-1}$. By contrast, the lowest-yielding hybrid (i.e., WSS3681) averaged 15.5 Mt.ha ${ }^{-1}$ (Table 2). In terms of gross profit margin, the top seven hybrids were comparable, averaging \$12,195/ ha to $\$ 13,189 /$ ha. Hybrid 1760 MRW was least profitable, averaging \$7600/ha.

Correlations. Days to midsilk was negatively correlated ( $\rho=-0.410$ to -0.598$)$ to several measures of the reproductive sink, including ear shoots/plant, marketable ears/ plant, ear mass/plant, kernel mass/plant, and recovery (Table 3 ). On an area basis, ear yield and gross profit margin also were negatively correlated with days to midsilk ( $\rho=-0.461$ and $\rho=-0.645$, respectively).

The LAI required to produce one case of sweet corn was negatively correlated ( $\rho=$ -0.409 to -0.595 ) with several crop responses, including marketable ears/plant, ear mass/plant, kernel mass/plant, and recovery. The LAI/case was negatively correlated with ear mass $(\rho=-0.697$ and gross profit margin $(\rho=-0.722)$.

Although ear length and filled ear length are highly related $(\rho=0.875)$, they have limited relationship to other measures of the sweet corn sink and no correlation to ear yield and gross profit margin (Table 3).

Optimal plant density. Plant density had a significant effect on ear yield and gross profit margin. Based on the quadratic model fit, predicted maximum responses and the plant density necessary for maximum responses were identified (Fig. 2). Ear yield was maximized at 5.5 plants $/ \mathrm{m}^{2}$, whereas gross profit margin was maximized at 6.1 plants $/ \mathrm{m}^{2}$.

Plant density observed in contract fields. A total of 586 fields were grown using a sh 2 processing hybrid, during the years 2000-15, where plant density had been quantified. Across all fields, the average plant density was 5.5 plants $/ \mathrm{m}^{2}$ (Fig. 2). The lower and upper interquartile

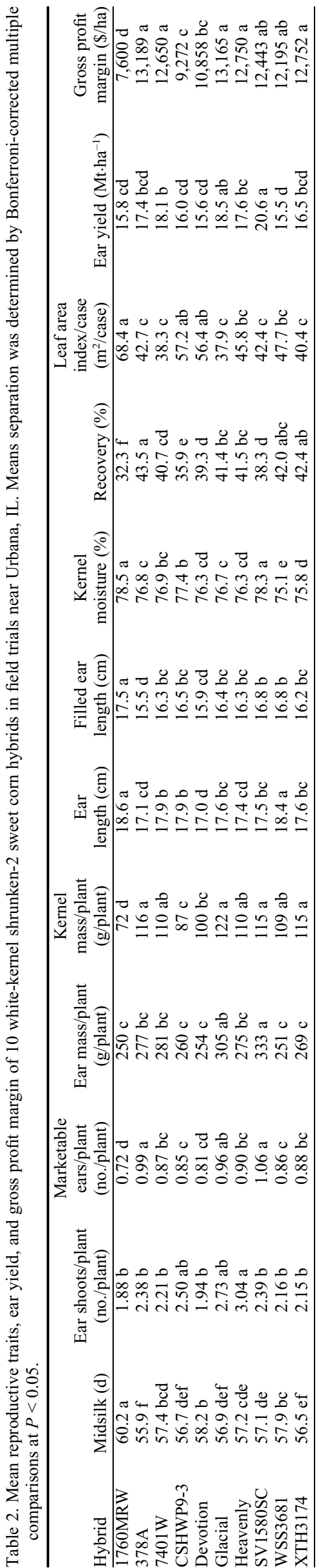


Table 3. Pearson correlation coefficients among reproductive traits, ear yield, and gross profit margin. Correlations in boldface type are significant at $P<0.05$.

\begin{tabular}{|c|c|c|c|c|c|c|c|c|c|c|c|}
\hline & Midsilk & Ear shoots/plant & $\begin{array}{c}\text { Marketable } \\
\text { ears/plant }\end{array}$ & $\begin{array}{c}\text { Ear } \\
\text { mass/plant }\end{array}$ & $\begin{array}{c}\text { Kernel } \\
\text { mass/plant }\end{array}$ & $\begin{array}{c}\text { Ear } \\
\text { length }\end{array}$ & $\begin{array}{c}\text { Filled } \\
\text { ear length }\end{array}$ & $\begin{array}{c}\text { Kernel } \\
\text { moisture }\end{array}$ & Recovery & $\mathrm{LAI} /$ case & $\begin{array}{l}\text { Ear } \\
\text { yield }\end{array}$ \\
\hline Ear shoots/plant & -0.452 & - & - & - & - & - & - & - & - & - & - \\
\hline Marketable ears/plant & -0.496 & 0.613 & - & - & - & - & - & - & - & - & - \\
\hline Ear mass/plant & -0.410 & 0.596 & 0.952 & - & - & - & - & - & - & - & - \\
\hline Kernel mass/plant & -0.598 & 0.561 & 0.893 & 0.891 & - & - & - & - & - & - & - \\
\hline Ear length & 0.290 & -0.017 & -0.091 & 0.039 & -0.081 & - & - & - & - & - & - \\
\hline Filled ear length & 0.267 & 0.002 & -0.047 & 0.101 & -0.062 & 0.875 & - & - & - & - & - \\
\hline Kernel moisture & 0.141 & 0.216 & 0.258 & 0.362 & -0.020 & 0.135 & 0.281 & - & - & - & - \\
\hline Recovery & -0.513 & 0.047 & -0.033 & -0.166 & 0.256 & -0.374 & -0.425 & -0.647 & - & - & - \\
\hline $\mathrm{LAI} /$ case & $\mathbf{0 . 5 0 7}$ & -0.343 & -0.534 & -0.471 & -0.595 & 0.274 & 0.179 & 0.008 & -0.409 & - & - \\
\hline Ear yield & -0.461 & 0.403 & 0.701 & 0.679 & 0.620 & -0.130 & -0.007 & 0.323 & 0.037 & -0.697 & - \\
\hline Gross profit margin & -0.645 & 0.237 & 0.388 & 0.274 & 0.585 & -0.335 & -0.324 & -0.414 & 0.763 & -0.722 & 0.634 \\
\hline
\end{tabular}

LAI = leaf area index.

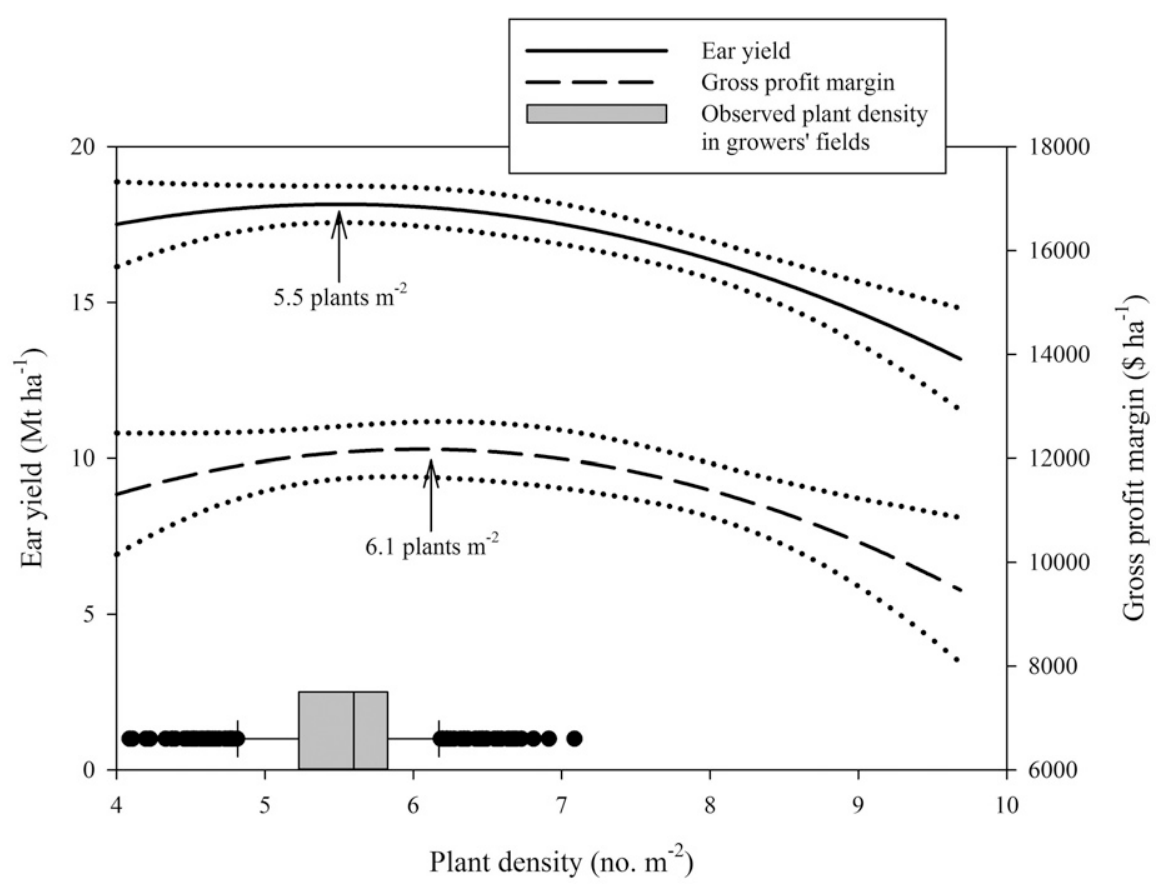

Fig. 2. Effect of plant density on ear yield and gross profit margin. Plant density effects are described with quadratic model, specifically, ear yield $=9.5441+3.1277 \times x+-0.2841 \times x^{2}$, and gross profit margin $=$ $4696.3+2473.1 \times x+-204.5 \times x^{2}$. Ninety-five percent confidence intervals are included. In addition, the distribution of plant densities observed in 586 growers' fields are included.

ranges were 5.2 and 5.8 plants $/ \mathrm{m}^{2}$, respectively.

\section{Discussion}

Treatments used in this study resulted in minimal crowding stress at the lowest plant density to significant crowding stress at the highest plant density. For instance at 4.3 plants $/ \mathrm{m}^{2}$, marketable ear number exceeded one ear/plant (Fig. 1B). Such prolificacy occurs in hybrids when there is minimal competition among neighboring plants (Hallauer, 1974). In the present work, crowding stress increased significantly beyond six plants $/ \mathrm{m}^{2}$ and prolificacy was suppressed, as evidenced by $<1$ ear/plant at higher plant densities (Fig. 1B). If these hybrids were grown for fresh market, plant density recommendations published by Morris et al. (2000) and Rangarajan et al. (2002) at the turn of the last century, specifically $5.4-6.1$ plants $/ \mathrm{m}^{2}$, appear to remain unchanged today.
Increasing plant density decreased the size of the reproductive sink of individual sweet corn plants. As plant density increased from 4.3 to 8.6 plants $/ \mathrm{m}^{2}$, linear decreases were observed in ear shoots and marketable ears per plant (Fig. 1B), ear length and filled ear length (Fig. 1C), and ear mass and kernel mass per plant (Fig. 1D). Effect of plant density on ear length, filled ear length, and ear mass per plant was similar to tests of sugaryl hybrids (Shelton and Tracy, 2013) and yellow-kernel sh2 hybrids (Williams, 2012). In sweet corn, this appears to be the first report of per-plant kernel mass loss with increasing plant density (loss of $18.1 \mathrm{~g} /$ plant) and results are comparable with findings in grain corn. When grain corn was grown under normal fertility conditions, kernel mass fell by $\approx 14.6 \mathrm{~g} /$ plant and $\approx 17.7 \mathrm{~g} / \mathrm{plant}$ for each additional plant $/ \mathrm{m}^{2}$ (Boomsma et al., 2009; Cox, 1996). Moreover, changes in the size of the reproductive sink of sweet corn corresponded to a delay in plant development. An extra $0.43 \mathrm{~d}$ to reach midsilk for each additional plant $/ \mathrm{m}^{2}$ (Fig. 1A) was consistent with previous reports of $\approx 1 / 2$-d delay in midsilk (Williams, 2012).

Reproductive traits vary widely among commercial white-kernel sh 2 hybrids. Ear mass ranged from 15.6 to $20.6 \mathrm{Mt} \cdot \mathrm{ha}^{-1}$, whereas recovery ranged from $32.3 \%$ to $42.4 \%$ (Table 2 ). Such yield differences have significant implications to contract growers, who are compensated based on ear yield. In addition, recovery is important to the sweet corn processor as a lower recovery not only reduces case production, but also increases the volume of waste (i.e., husks and cobs) going through the processing plant. Although recovery is rarely measured and reported in the literature, these data show that recovery provides a more complete picture of hybrid performance. For instance, WSS3681 had the lowest ear yield of all hybrids; however, the hybrid's gross profit margin was comparable with the most profitable hybrids because of its high recovery (Table 2 ). Indeed, across hybrids, recovery had the highest correlation with gross profit margin $(\rho=0.763)$. Recovery in sweet corn could be considered analogous to harvest index (HI) in grain corn, which is the fraction of grain mass to plant mass. At optimum plant densities, $\mathrm{HI}$ of grain corn has not changed since the development of hybrid corn (Duvick, 2005). By contrast, recovery has improved in sweet corn, as evidenced by the fact that recovery averaged $30 \%$ in 1950 (Huelson, 1954). Consistent with the findings of the present research, today's sweet corn hybrids average $38 \%$ recovery, with some exceeding $46 \%$ (Williams, 2015).

Leaf area index/case provides an estimate of efficiency of the plant at converting sunlight to kernel mass. A large value indicates low efficiency due to the large amount of leaf area required to produce one case of sweet corn product, whereas a small value indicates high efficiency. Nearly 2-fold difference in $\mathrm{LAI} /$ case among hybrids reveals large differences in efficiency among hybrids. Interestingly, the second highest correlation with gross profit margin was LAI/ case $(-0.722)$, which is numerically higher than the correlation $(-0.620)$ between LAI and grain yield reported by Mansfield and Mumm (2014).

Among hybrids tested here, there appears to be no yield benefit of later-maturing hybrids. For instance, 1760MRW had the 
latest midsilk date, yet was among the lowest yielding and least profitable hybrids. In other plant density tolerance research in Illinois, processing hybrids requiring $>80 \mathrm{~d}$ to mature were among the poorest performing (Williams, 2015).

Although white-kernel sh2 hybrids differ in reproductive traits, they have a common response to plant density, as evidenced by lack of significant interaction between hybrid and plant density $(P \geq 0.870)$. Ear yield was optimized at 5.5 plants $/ \mathrm{m}^{2}$ and gross profit margin was optimized at 6.1 plants $/ \mathrm{m}^{2}$ (Fig. 2). If data from growers' fields reflect actual plant densities that white-kernel hybrids are being grown, then the reproductive sink size is currently optimized for today's white-kernel hybrids. Unfortunately, there may have been no improvement in plant density tolerance over the last 2 decades.

Debate continues on the extent to which further improvements in plant density tolerance can improve grain corn productivity (Egli, 2015; Lobell et al., 2014; Mansfield and Mumm, 2014). Alternative solutions, such as increasing ear size or prolificacy, may not be an option in sweet corn. In the present work, longer ears did not contribute to recovery, and ear length had no relationship to ear yield or gross profit margin. Moreover, prolificacy in sweet corn is an indication the crop is not fully capturing resources available to optimize yield, and subapical ears reduce recovery in the processing plant (Williams, 2014). In the meantime, this research shows plant density tolerance could be improved in white-kernel sh2 sweet corn. In related research, yellowkernel sh 2 hybrids have a wider response to plant density. Among widely used yellowkernel sh2 processing hybrids, optimum populations ranged from 4.8 to 7.0 plants $/ \mathrm{m}^{2}$ (Williams, 2012). Relative to other processing sweet corn, ear yield and profitability of the white-kernel sh 2 hybrids tested here were below average and none of the hybrids had noticeably high plant density tolerance. Grown under nearly identical conditions to this study but at 7.2 plants $/ \mathrm{m}^{2}$, ear yield of many other sh 2 processing hybrids exceeded $20 \mathrm{Mt} \cdot \mathrm{ha}^{-1}$ and gross profit margin of the most profitable hybrids exceeded \$15,000/ha (Williams, 2015). If other types of corn-including sweet corn-serve as a valid example, then improvements in plant density tolerance in white-kernel sh2 hybrids will increase yield and profitability.

\section{Literature Cited}

Boomsma, C.R., J.B. Santini, M. Tollenaar, and T.J. Vyn. 2009. Maize morphophysiological responses to intense crowding and low nitrogen availability: An analysis and review. Agron. J. 101:1426-1452.

Cox, W.J. 1996. Whole-plant physiological and yield responses of maize to plant density. Agron. J. 88:489-496.

Duvick, D.N. 2005. The contribution of breeding to yield advances in maize (Zea mays L.). Adv. Agron. 86:83-145.

Egli, D.B. 2015. Is there a role for sink size in understanding maize population-yield relationships? Crop Sci. 55:2453-2462.

Hallauer, A.R. 1974. Heritability of prolificacy in maize. J. Hered. 65:163-168.

Huelson, W.A. 1954. Sweet corn. Interscience Publ., New York, NY.

Lee, E.A. and M. Tollenaar. 2007. Physiological basis of successful breeding strategies for maize grain yield. Crop Sci. 47:S202-S215.

Lobell, D.B., M.J. Roberts, W. Schlenker, N. Braun, B.B. Little, R.M. Rejesus, and G.L. Hammer. 2014. Greater sensitivity to drought accompanies maize yield increase in the U.S. Midwest. Science 344:516-519.

Mansfield, B.D. and R.H. Mumm. 2014. Survey of plant density tolerance in U.S. maize germplasm. Crop Sci. 54:157-173.

Morris, T.F., G. Hamilton, and S. Harney. 2000. Optimum plant population for fresh-market sweet corn in the northeastern United States. HortTechnology 10:331-336.

National Corn Growers Association. 2014. 30 Mar. 2017. $<$ http://www.ncga.com/upload/files/documents/ $\mathrm{pdf} / \mathrm{ncyc} /$ Yield-Guide-2014.pdf $>$.

Neter, J., M.H. Kutner, C.J. Nachtsheim, and W. Wasserman. 1996. Applied linear statistical models. 4th ed. Irwin, Chicago, IL.

Rangarajan, A., B. Ingall, M. Orfanedes, and D. Wolfe. 2002. In-row spacing and cultivar affects ear yield and quality of early-planted sweet corn. HortTechnology 12:410-415.

Rogers, I.S. and G.J. Lomman. 1988. Effects of plant spacing on yield, size and kernel fill of sweet corn. Austral. J. Expt. Agr. 28:787-792.

SAS Institute. 2010. Version 9.3. SAS Inst., Cary, NC.

Shelton, A.C. and W.F. Tracy. 2013. Genetic variation and phenotypic response of 15 sweet corn (Zea mays L.) hybrids to population density. Sustainability 5:24422456.

Smith, S., M. Cooper, J. Gogerty, C. Loffler, D. Borcherdung, and K. Wright. 2014. Maize, p. 125-171. In: S. Smith, B. Diers, J. Specht, and B. Carver (eds.). Yield gains in major U.S. field crops. Crop Sci. Soc. Amer., Madison, WI.

Tetio-Kagho, F. and F.P. Gardner. 1988. Responses of maize to plant population density. II. Reproductive development, yield, and yield adjustments. Agron. J. 80:935-940.

Tracy, W.F. 1993. Sweet corn, Zea mays L., p. 777-807. In: G. Kalloo and B.O. Bergh (eds.). Genetic improvement of vegetable crops. Pergamon Press, Oxford, UK.

Williams, M.M., II. 2012. Agronomics and economics of plant population density on processing sweet corn. Field Crops Res. 128:55-61.

Williams, M.M., II. 2014. Few crop traits accurately predict variables important to productivity of processing sweet corn. Field Crops Res. 157:20-26.

Williams, M.M., II. 2015. Relationships among phenotypic traits of sweet corn and tolerance to crowding stress. Field Crops Res. 185: $45-50$. 